\title{
TEP versus Lichtenstein, which one to choose? A retrospective cohort study
}

\author{
Durat Urkan ${ }^{1}$ \\ Yasar Subutay Peker ${ }^{1}$
}

1. University of Medical Sciences, Gulhane Training and Research Hospital, Department of General Surgery, Ankara / Turkey

http://dx.doi.org/10.1590/1806-9282.65.9.1201

\begin{abstract}
SUMMARY
OBJECTIVES: Inguinal hernioplasty techniques have been improved since the first hernioplasty. Tension-free techniques that apply synthetic mesh materials, as in the Lichtenstein approach, are the gold standard. Laparoscopic hernioplasty is the strongest alternative to Lichtenstein. The superiority of laparoscopic hernioplasty over Lichtenstein is a major topic of debate. In this study, we aimed to find a conclusion to this debate by comparing our totally extraperitoneal (TEP) experiences with Lichtenstein experiences.
\end{abstract}

METHODS: Patients who underwent inguinal hernioplasty at the Gulhane Training and Research Hospital from 2013 to 2018 were included in this retrospective cohort study. The sample included 96 TEP and 90 Lichtenstein patients for a total of 186 patients. The variables assessed were hospitalization duration, postoperative early visual analog scale score, chronic pain, paresthesia, recurrence, and early postoperative complications. Data were collected from patient records and via telephone questionnaire if needed. Data analysis was done by SPSS V2O, using chi-square, Fisher's exact, and Mann-Whitney U tests.

RESULTS: Male/female ratios were similar between the TEP and Lichtenstein groups. There was no difference in mean age between groups $(p=0.1)$. The hospital stay was shorter $(p=0.0001)$, and early postoperative visual analog scale score was lower in the TEP group $(p=0.003)$. Chronic pain, paresthesia, recurrence, and early postoperative complications (hematoma, seroma, wound infection) were similar.

CONCLUSIONS: TEP is superior to Lichtenstein with shorter hospitalization duration and lower rates of early postoperative pain. No difference between the two techniques was found for chronic pain. We believe that laparoscopic hernioplasty approach may be the best alternative technique for inguinal hernia repair.

KEYWORDS: Herniorrhaphy. Laparoscopy. Hernia, Inguinal/surgery.

\section{INTRODUCTION}

Inguinal hernia repair is one of the most common surgical procedures performed by general surgeons. The technique used for inguinal hernias has changed since the beginning of hernia repair, with the first hernia terminology defined in 1552 B.C. in Erb's papyrus'. Many techniques have since been described for inguinal hernia repair, and many modifications have been applied to these techniques. After the invention of biocompatible synthetic meshes, new techniques such as Lichtenstein, offering tension-free hernioplasty with low rates of recurrence and high postoperative quality of life, became the

DATE OF SUBMISSION: 31-Mar-2019

DATE OF ACCEPTANCE: 19-Apr-2019

CORRESPONDING AUTHOR: Yasar Subutay Peker

Gulhane Training and Research Hospital Dept Of Surgery

Gen Tevfik Saglam Blvd No:1 - Etlik Kecioren - Ankara - Turkey - 06010

Email: subutaypeker@gmail.com 
gold standard for inguinal hernioplasties. However, a low recurrence rate and high postoperative quality of life are not the only parameters in achieving excellent inguinal hernia repair. Length of hospital stay, postoperative complication rate, and cost are also important in determining the perfect hernioplasty technique.

Lichtenstein was the tension-free gold standard technique for hernia repair but regressed from being a favorite when minimally invasive approaches in surgery came into fashion. Laparoscopic hernioplasty techniques such as totally extra-peritoneal (TEP) and trans-abdominal pre-peritoneal (TAPP) are accepted by many surgeons and have begun to be applied in many centers. As a result of recent developments in hernia repair, the current major debate about inguinal hernioplasty is which technique is more feasible, a tension-free open conventional technique or a laparoscopic technique, although both are accepted as standard methods of inguinal hernia repair $^{2}$. The conventional technique currently insists on a tension-free approach, and the most commonly applied is Lichtenstein. TAPP and TEP are tension free also because no repair is applied to the hernia defect; instead, a mesh is laid over the defect and fixed to the fascia in current laparoscopic techniques (Figure 1-3).

Conventional tension-free repair (Lichtenstein) was first described in 1989 for anterior mesh hernioplasty $^{3}$. Laparoscopic techniques, however, are used for posterior hernioplasty, which is built upon the Stoppa et al. ${ }^{4}$ approach with the development of laparoscopic technologies. Studies have shown that the major advantage of laparoscopic repair over conventional repair is its shorter recovery times and hospital length of stay ${ }^{5,6}$.

Laparoscopic approaches also have the advantage of better cosmetic results with a 3-trocar approach to the abdomen, for an 11 to $25 \mathrm{~mm}$ incision instead of the average 50 to $80 \mathrm{~mm}$ incision. Differences between the two techniques in terms of other parameters such as relapses, postoperative visual analog scale (VAS) scores, and complication rates are still being debated; no consensus has been reached because the experience of the surgeon and the surgical techniques used can affect the balance ${ }^{7-9}$. Thus, in our study, we compared the TEP technique, which is used as a laparoscopic technique, in our center with the Lichtenstein repair. Operations were performed by two experienced hernia surgeons with standard- ized techniques, and results were compared for the parameters that are currently debated.

\section{METHODS}

Patients who underwent hernia repair by two surgeons at the Gulhane Training and Research Hospital between January 2013 and April 2018 were included in the study. Both surgeons applied polypropylene-based meshes and fixated them with laparoscopic fixators as tacks, instead of intracorporal saturation. Data of the patients were collected retrospectively from hospital records, and postoperative long-term follow-up data were collected by telephone questionnaire. Our study is a retrospective cohort study that included follow-up results of 96 TEP and 90 Lichtenstein procedures, for a total of 186 patients who underwent hernioplasty. The mean follow-up duration was 21.93 months. Demographic data such as age and sex and data related to the type of the hernia, postoperative VAS score, conversion to the conventional technique, early postoperative complications, hospitalization duration, and type of surgery were obtained from hospital records. Long term follow-up parameters, including chronic pain, paresthesia, and relapse, were collected by telephone questionnaire and by radiological test results if needed. All data obtained were noted on patient sheets and were organized in Microsoft Excel 2010 (Redmond, Washington, U.S.). The independent variable in this study was the type of surgery (TEP or Lichtenstein), and the dependent variables were postoperative hospitalization duration, VAS score, chronical pain, paresthesia, relapse, and early postoperative complications. Data analysis was done using SPSS v.20 (New York, U.S.). Chi-square, Fisher's exact, and Mann-Whitney $\mathrm{U}$ tests were used for statistical evaluation.

\section{RESULTS}

Our study compared only newly diagnosed inguinal hernias repaired with the TEP or Lichtenstein technique. No recurrent hernias were evaluated in our study. The 186 patients in the study had inguinal hernioplasty for direct, indirect, or combined inguinal hernia. None of the patients had femoral hernias. A total of 96 (51.6\%) patients were operated with the TEP technique and 90 (48.4\%) with the Lichtenstein conventional technique. None of the TEP operations were converted to Lichtenstein, so there was no con- 


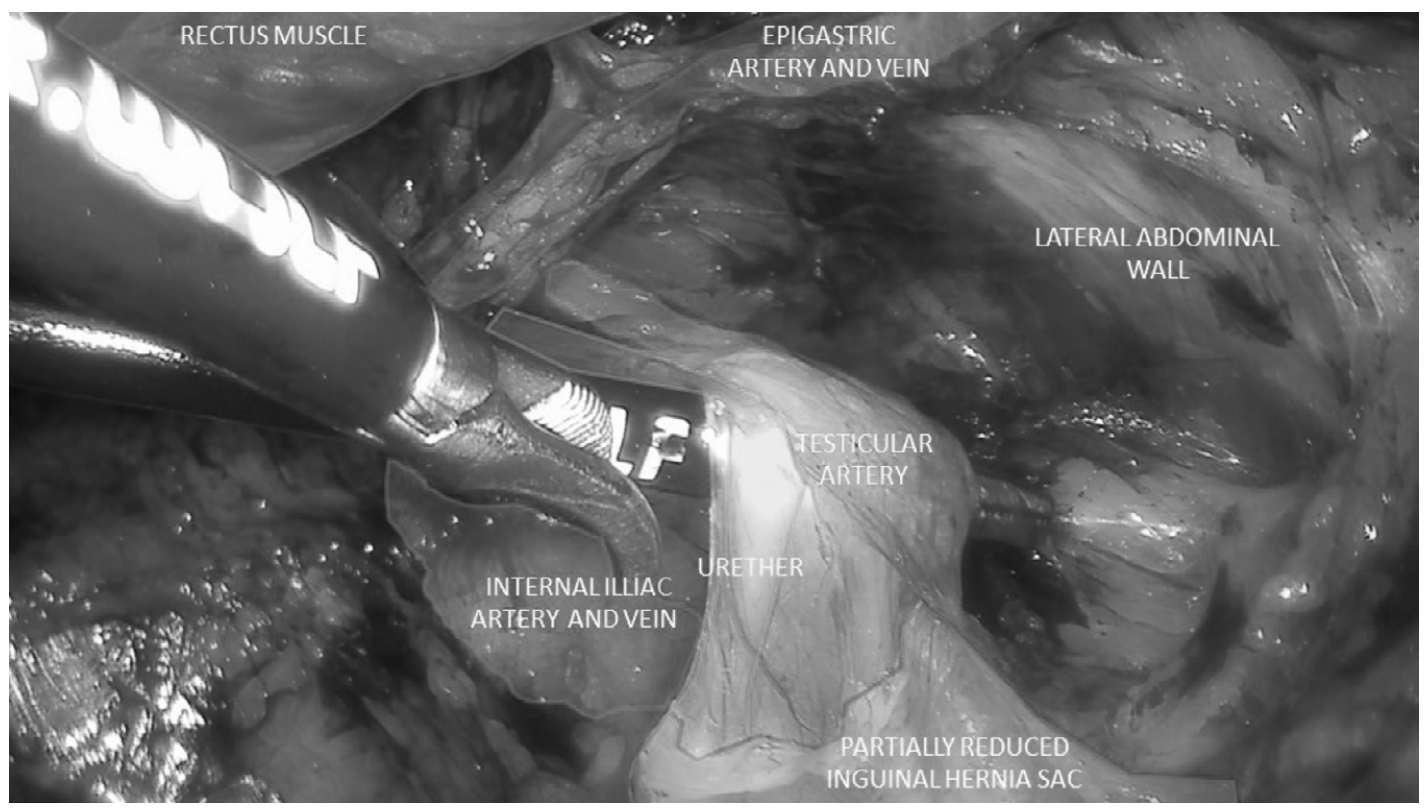

FIGURE 1

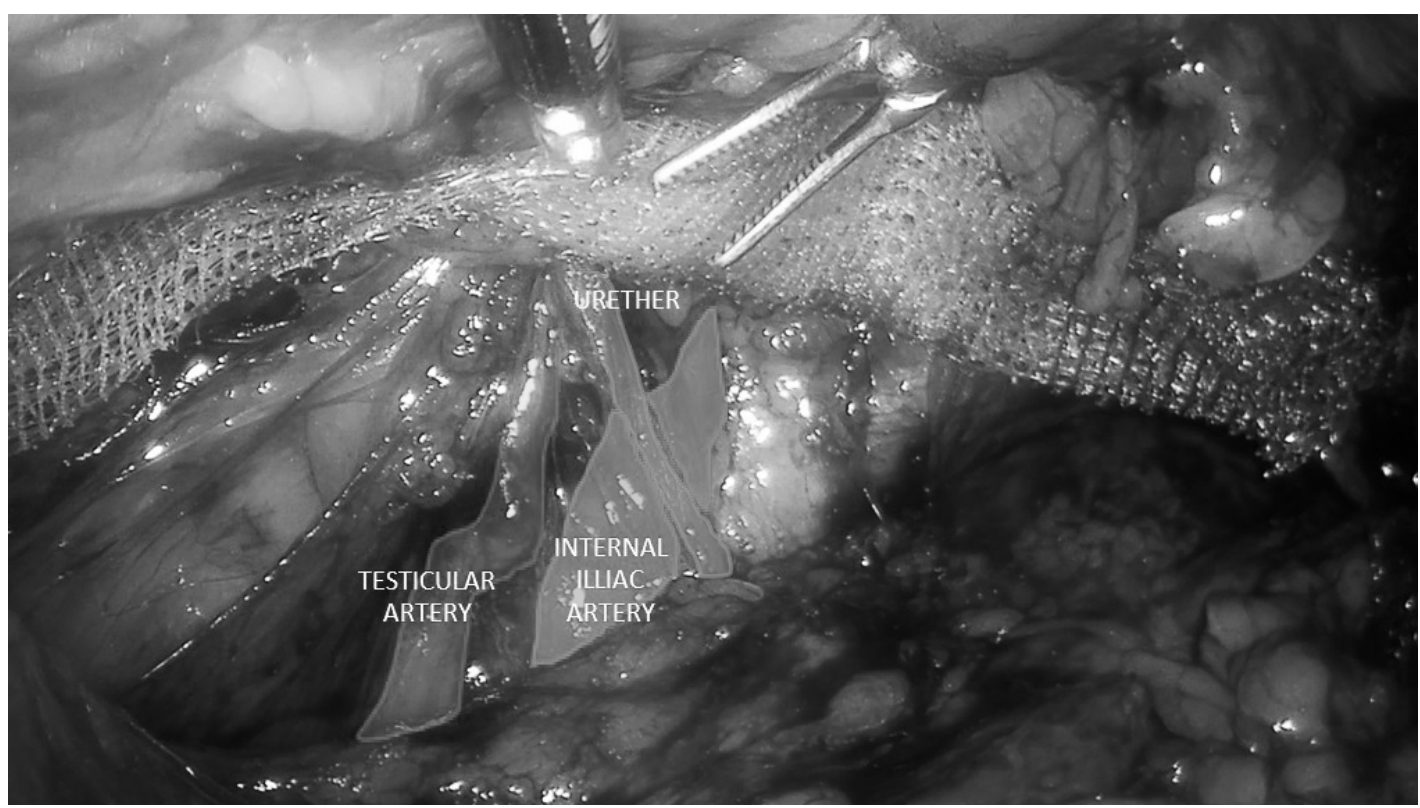

FIGURE 2

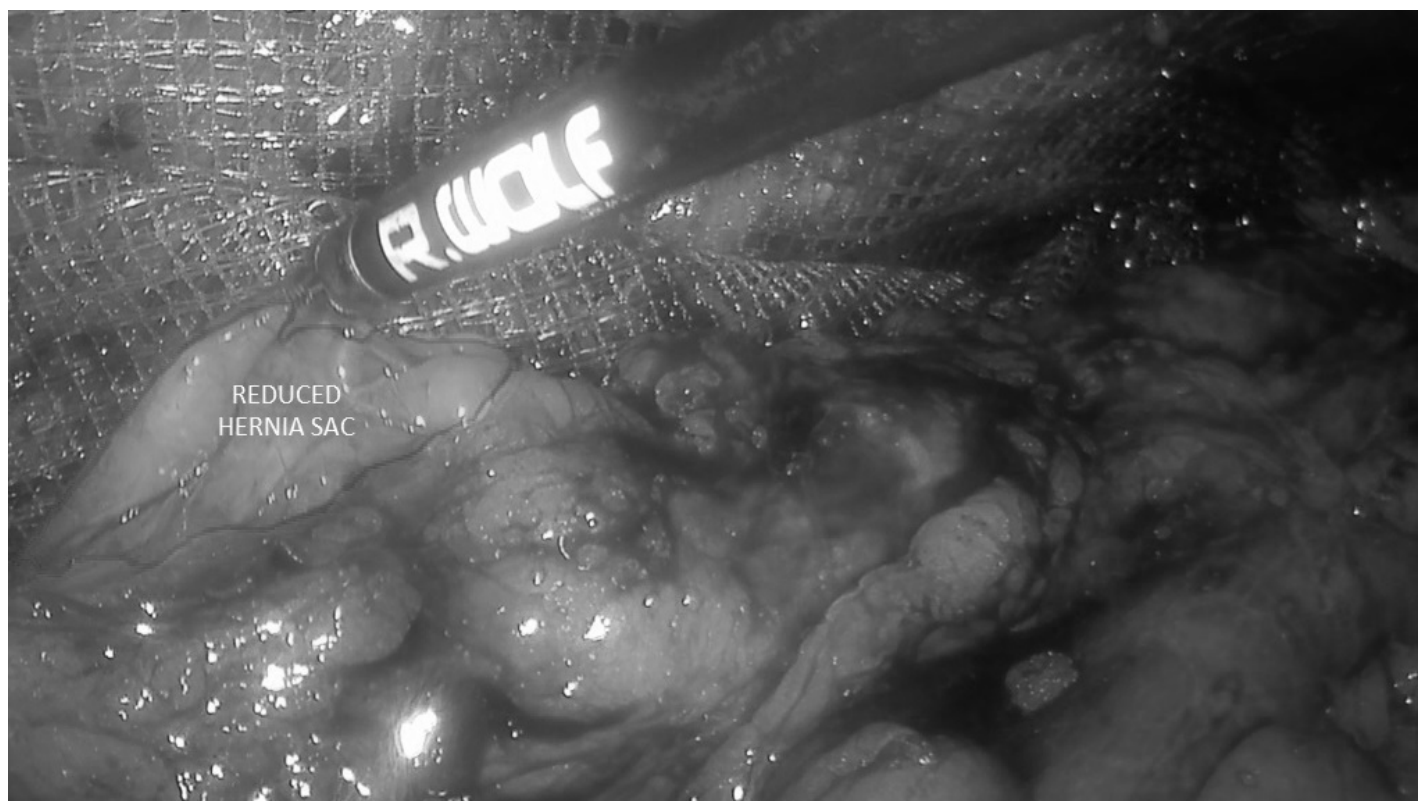

FIGURE 3 
version to open hernioplasty. The mean follow-up duration was 21.93 (3-66) months. Ten (10.4\%) patients from the TEP group and 9 (10.0\%) from the Lichtenstein group, totaling 19 (10.2\%) patients, underwent surgery for bilateral inguinal hernia. These patients were considered to have one hernia, and relapses or complications that occurred on one side or both sides were considered a relapse or complication.

The gender of the patients was analyzed; 171 $(91.9 \%)$ were male, and 15 (8.1\%) female. We found no statistically significant difference between the two groups in terms of gender $(\mathrm{X} 2=.881, \mathrm{p}=0.348)$.

The mean age of the patients was 48.7 (18.0-83.7) years. The mean age was 46.7 (18.0-80.3) years for the TEP group and 50.8 (19.9-83.7) for the Lichtenstein group. There was no statistical difference between the groups $(\mathrm{p}=0.1)$. Mean length of hospital stay was 2.0 days (1-7): 1.6 (1-5) days for the TEP group and 2.4 (1-7) for the Lichtenstein group. The difference between the two groups was statistically significant $(\mathrm{p}=0.0001)$. Patients were evaluated on the postoperative day 1 for the VAS score. The mean VAS score was 1.9 (1-5) for the TEP group and 2.3 (1-5) for the Lichtenstein group. The difference between the two groups was statistically significant $(p=0.003)$ (Table 1).

Patients were evaluated for chronic pain, paresthesia, and relapse; 24 (12.9\%) patients reported postoperative chronic pain of different severities, 9 (9.3\%) from the TEP group and 15 (16.6\%) from the Lichtenstein group. There was no statistically significant difference between groups $(\mathrm{x} 2=2.198, \mathrm{p}=0.138)$. The two groups were evaluated for postoperative long-term paresthesia. A total of $19(10.2 \%)$ patients had paresthesia, 6 (6.3\%) from the TEP group, and 13 (14.4\%) from the Lichtenstein group. There was no significant difference between the two groups ( $\mathrm{x} 2=3.40$, $\mathrm{p}=0.065)$.

Total relapses were seen in $8(4.30 \%)$ patients, 3 (3.13\%) from the TEP group, and 5 (5.56\%) from the Lichtenstein group. Relapses were confirmed with ultrasound, and there was no significant difference between the groups (Fisher exact test, $p=0.48$ ). Relapses were re-operated according to patient's request by the same surgeon with the open technique.

Postoperative early complications (hematoma, seroma, and wound infection) were evaluated (Table 2). There were no significant differences between the two groups according to total postoperative complications $(\mathrm{x} 2=0.334, \mathrm{p}=0.563)$.

\section{DISCUSSION}

Inguinal hernia is one of the most common ailments treated by general surgeons. For this reason, determining the best hernioplasty technique affects many people. Recent consensus for inguinal hernioplasty is on a tension-free approach due to its low recurrence rates and better postoperative quality of life ${ }^{1}$. Liechtenstein has been the gold standard for conventional tension-free hernioplasties for more than three decades ${ }^{11,12}$. Because a minimally invasive surgical approach is the currently preferred approach for many operations, TEP is debated as the new gold standard for hernioplasty if expertise is available ${ }^{2}$. As a result, comparing the conventional Liechtenstein technique with minimally invasive TEP is a vital topic.

A total of 186 patients, 96 with TEP and 90 with Liechtenstein, were compared for age and sex, and no statistically significant difference was found $(p=0.1, p=0.34$ respectively). The two groups were also similar in terms of the rate of bilateral hernioplasties (10\%). As a result of these similarities, the two groups were suitable for comparison of the remaining parameters.

The two groups were compared for hospitalization duration, which was statistically significantly shorter in the TEP group than in the Lichtenstein group ( $p=0.0001)$. Short hospitalization duration may be an indicator of lower complication rates and enhanced recovery. Even though TEP is accepted as a higher-cost operation than Lichtenstein ${ }^{13}$, enhanced recovery after TEP may decrease its cost. Further cost analysis should be done to reach a conclusion'.

According to our results, postoperative early VAS scores were lower in the TEP group $(\mathrm{p}=0.003)$ (Table 1), as in the study by O'Reilly et al. ${ }^{1}$ This is also the probable reason for the statistically significant lower length of hospital stay in the TEP group. However,

TABLE 1. DISTRIBUTION OF AGE, LENGTH OF STAY, AND POSTOPERATIVE VAS SCORES OF THE PATIENTS.

\begin{tabular}{l|l|l|l|l} 
& $\begin{array}{l}\text { TEP } \\
\text { Mean } \\
\text { (min-max) }\end{array}$ & $\begin{array}{l}\text { Lichtenstein } \\
\text { Mean } \\
\text { (min-max) }\end{array}$ & $\begin{array}{l}\text { Total } \\
\text { Mean } \\
\text { (min-max) }\end{array}$ & $p$ value \\
\hline Age (years) & $\begin{array}{l}46.7(18- \\
80)\end{array}$ & $50.8(19-83)$ & $48.7(18-83)$ & $p=0.1$ \\
\hline $\begin{array}{l}\text { Length of stay } \\
\text { (days) }\end{array}$ & $1.60(1-5)$ & $2.44(1-7)$ & $2.01(1-7)$ & $p=0.0001$ \\
\hline $\begin{array}{l}\text { Postoperative } \\
\text { VAS score }\end{array}$ & $1.93(1-5)$ & $2,30(1-5)$ & $2,10(1-5)$ & $p=0.003$ \\
\hline $\begin{array}{l}\text { Murat URKAN et al } \\
\text { Mut }\end{array}$ & \multicolumn{3}{|l}{} \\
\hline
\end{tabular}


the main debate in comparing open hernioplasty to laparoscopic hernioplasty is not early postoperative pain but chronic postoperative pain, which is one of the major complications of inguinal hernioplasty. Our study found lower chronic postoperative pain in the TEP group (9.3\%) than in the Lichtenstein group (16.6\%), as in many studies, but there was no statistically significant difference between the groups.

Manangi et al.' studied the reasons for postoperative pain after inguinal hernioplasty and found that preoperative pain is statistically strongly significant for the development of postoperative pain, which probably is related to the patient's pain threshold level. The relationship of preserving or scarifying the regional sensory nerves at the operation site is a matter of debate for postoperative chronic pain. Some studies conclude that preserving or scarifying nerves increases chronic postoperative pain; for this reason, prophylactic neurectomy and pragmatic neurectomy are being debated, without any high-quality evidence $^{17-19}$. This is a debate for neuropathic pain. The incorporation of nerves with staplers, sutures, or mesh is another major cause of neuropathic postoperative chronic pain. Ilioinguinal, iliohypogastric, genitofemoral, and lateral femoral cutaneous nerves are commonly involved. Somatic pain can also be the reason for postoperative pain. Reaction to the prosthetic mesh material, osteitis pubis, and tendon-muscle injuries during surgery may be the reason why somatic pain is more common than neuropathic pain ${ }^{2}$.

TEP has an advantage over Lichtenstein because it interferes less with the chronic pain etiologies discussed above. Because TEP is a posterior hernioplasty, the surgeon is unlikely to dissect regional sensory nerves. As a note, surgeons must be careful of the pain triangle during TEP. Also, staplers and sutures applied for mesh fixation in TEP can barely incorporate the nerves. Furthermore, because no primary repair to the hernia defect is applied through muscles and tendons, the incidence of somatic pain also decreases. All these factors also decrease the rate of early postoperative pain. However, we could not find a statistically significant difference between postoperative chronic pain with open and laparoscopic inguinal hernioplasty.

Laparoscopic posterior hernioplasty has the advantage of less muscle and tendon injury during dissection and lower incorporation of regional sensory nerves, which may result in less postoperative paresthesia. As our clinic routine, we give importance to preserving the local sensory nerves during Lichtenstein hernioplasty. We have a lower rate of postoperative paresthesia with TEP (6.3\%) than with Lichtenstein $(14.4 \%)$, but there was no statistically significant difference between the two groups $(p=0.065)$. Douek et al. ${ }^{21}$ studied paresthesia in open vs. laparoscopic inguinal hernioplasty and found that 12 of 242 patients had paresthesia five years after hernioplasty, which decreases the quality of life of the patients. All patients with paresthesia underwent open hernioplasty, and they concluded that the laparoscopic approach is strongly related to lower rates of postoperative paresthesia. Our study confirms the findings of Douek et al. ${ }^{21}$, but unfortunately, we could not prove this statistically. Postoperative recurrence rates of both groups were in acceptable ranges, and there was no statistically significant difference between them $(p=0.48)$ (Table 2 ). One of the largest systemic reviews on the topic by McCormack et al. ${ }^{22}$, with 7161 patients from 41 studies in 2003 , found no statistically significant difference for postoperative hernia recurrence between open and laparoscopic hernioplasty approaches $(\mathrm{p}=0.16)$, as in this study. The laparoscopic approach had the same or lower recurrence rates compared with the Lichtenstein technique, which endorses the laparoscopic technique for becoming the gold

TABLE 2. POSTOPERATIVE COMPLICATIONS PER HERNIOPLASTY TECHNIQUE.

\begin{tabular}{l|l|l|l|l} 
Type of complication & TEP $n(\%)$ & Lichtenstein $n(\%)$ & Total $n(\%)$ & $p$-value \\
\hline Chronical pain & $9(\% 9.3)$ & $15(\% 16.6)$ & $24(\% 12.9)$ & $p=0.138$ \\
\hline Long term paresthesia & $6(\% 6.25)$ & $13(\% 14.44)$ & $19(\% 10.21)$ & $p=0.065$ \\
\hline Relapse hernia & $3(\% 3.13)$ & $5(\% 5.56)$ & $8(\% 4.3)$ & $p=0.48$ \\
\hline $\begin{array}{l}\text { Postoperative early complications (Hematoma, } \\
\text { seroma, wound infection) }\end{array}$ & $11(\% 11.4)$ & $8(\% 8.8)$ & $19(\% 10.2)$ & $p=0.563$ \\
\hline
\end{tabular}


standard in inguinal hernioplasty. However, in 2012, O'Reilly et al. ' found that the recurrence rate of TAPP is equal to that of the open technique and is statistically higher than the other two techniques. The common attitude about recurrence rates of hernioplasty according to current data is that they are accepted as equal for laparoscopic and open hernioplasty techniques.

The TEP and Lichtenstein groups were compared for early postoperative complications such as hematoma, seroma, and operation site infections, and there was no statistically significant difference between the two groups ( $p=0.563$ ) (Table 2). Koning et al. ${ }^{23}$ studied severe adverse effects of hernioplasty with the conventional and laparoscopic techniques; their systematic review showed that there is no significant difference between them in terms of severe adverse effects.

\section{CONCLUSION}

In conclusion, chronic pain, long-term paresthesia, relapses, and early postoperative complications were not different between the groups. The major differences between the groups were early postoperative VAS scores and length of stay, which were lower in the TEP group. These results may be the reason why surgeons prefer a minimally invasive hernioplasty approach instead of the conventional technique and why the minimally invasive approach should become the gold standard hernioplasty technique.

\section{Authors Contribution}

Yasar Subutay Peker was responsible for data analysis and writing the manuscript, and Murat Urkan was responsible for data collection and final revision of the manuscript.

\section{RESUMO}

OBJETIVOS: As técnicas de hernioplastia inguinal foram melhoradas desde a primeira hernioplastia. Técnicas livres de tensão que aplicam materiais de malha sintética, como na abordagem de Lichtenstein, são o padrão ouro. A hernioplastia laparoscópica é a alternativa mais forte ao Lichtenstein. A superioridade da hernioplastia laparoscópica sobre o Lichtenstein é um dos principais temas debatidos. Neste estudo, procuramos encontrar uma conclusão para esse debate comparando nossas experiências totalmente extraperitoneais (TEP) com as experiências de Lichtenstein.

MÉTODOS: Pacientes submetidos à hernioplastia inguinal no Gulhane Training and Research Hospital de 2013 a 2018 foram incluídos neste estudo de coorte retrospectivo. A amostra incluiu 96 pacientes TEP e 90 pacientes Lichtenstein para um total de 186 pacientes. As variáveis avaliadas foram tempo de internação, escore da escala analógica visual precoce no pós-operatório, dor crônica, parestesia, recidiva e complicações pós-operatórias precoces. Os dados foram coletados dos prontuários e do questionário por telefone, se necessário. A análise dos dados foi realizada pelo SPSS v20, utilizando os testes qui-quadrado, exato de Fisher e U de Mann-Whitney.

RESULTADOS: As razões homem/mulher foram semelhantes entre os grupos TEP e Lichtenstein. Não houve diferença na média de idade entre os grupos $(p=0,1)$. A permanência hospitalar foi menor $(p=0,1)$ e a escala visual analógica precoce foi menor no grupo TEP $(p=0,003)$. Dor crônica, parestesia, recorrência e complicações pós-operatórias imediatas (hematoma, seroma, infecção da ferida) foram semelhantes.

CONCLUSÕES: O TEP é superior ao Lichtenstein, com menor tempo de internação e menores taxas de dor pós-operatória precoce. Nenhuma diferença entre as duas técnicas foi encontrada para dor crônica. Acreditamos que a abordagem de hernioplastia laparoscópica pode ser a melhor técnica alternativa para correção de hérnia inguinal.

PALAVRAS-CHAVE: Herniorrafia. Laparoscopia. Hérnia inguinal/cirurgia.

\section{REFERENCES}

1. Skandalakis LJ. Skandalakis surgical anatomy: the embryologic and anatomic basis of modern surgery. Athens: Paschalidis Periklis Ch Ltd Medical Publications; 2008.

2. Simons MP, Aufenacker T, Bay-Nielsen M, Bouillot JL, Campanelli G, Conze J, et al. European Hernia Society guidelines on the treatment of inguinal hernia in adult patients. Hernia. 2009;13(4):343-403.

3. Lichtenstein IL, Shulman AG, Amid PK, Montllor MM. The tension-free hernioplasty. Am J Surg. 1989;157(2):188-93.

4. Stoppa R, Petit J, Henry X. Unsutured Dacron prosthesis in groin hernias. Int Surg. 1975;60(8):411-2.
5. Wake BL, McCormack K, Fraser C, Vale L, Perez J, Grant AM. Transabdominal pre-peritoneal (TAPP) vs totally extraperitoneal (TEP) laparoscopic techniques for inguinal hernia repair. Cochrane Database Syst Rev. 2005; (1):CD004703.

6. Myers E, Browne KM, Kavanagh DO, Hurley M. Laparoscopic (TEP) versus Lichtenstein inguinal hernia repair: a comparison of quality-of-life outcomes. World J Surg. 2010;34(12):3059-64.

7. Schmedt CG, Sauerland S, Bittner R. Comparison of endoscopic procedures vs Lichtenstein and other open mesh techniques for inguinal hernia repair: a meta-analysis of randomized controlled trials. Surg Endosc. 2005;19(2):188-99 
8. Eklund AS, Montgomery AK, Rasmussen IC, Sandbue RP, Bergkvist LA, Rudberg CR. Low recurrence rate after laparoscopic (TEP) and open (Lichtenstein) inguinal hernia repair: a randomized, multicenter trial with 5-year follow-up. Ann Surg. 2009;249(1):33-8.

9. Butters M, Redecke |, Köninger |. Long-term results of a randomized clinical trial of Shouldice, Lichtenstein and transabdominal preperitoneal hernia repairs. Br J Surg. 2007;94(5):562-5.

10. HerniaSurge Group. International guidelines for groin hernia management. Hernia. 2018;22(1):1-165.

11. Bay-Nielsen M, Kehlet H, Strand L, Malmstrøm J, Andersen FH, Wara P, et al. Quality assessment of 26,304 herniorrhaphies in Denmark: a prospective nationwide study. Lancet. 2001;358(9288):1124-8

12. Bay-Nielsen M, Thomsen $H$, Andersen FH, Bendix JH, Sørensen OK, Skovgaard N, et al. Convalescence after inguinal herniorrhaphy. Brit / Surg. 2004;91:362-7.

13. lelpo B, Nuñez-Alfonsel I, Duran H, Diaz E, Fabra I, Caruso R, et al. Cost-effectiveness of randomized study of laparoscopic versus open bilateral inguinal hernia repair. Ann Surg. 2018;268(5):725-30

14. Roos MM. Improving TEP inguinal hernia repair [Dissertation]. Utrecht: Utrecht University; 2018

15. O'Reilly EA, Burke JP, O'Connell PR. A meta-analysis of surgical morbidity and recurrence after laparoscopic and open repair of primary unilateral inguinal hernia. Ann Surg. 2012;255(5):846-53.

16. Manangi M, Shivashankar S, Vijayakumar A. Chronic pain after inguinal hernia repair. Int Sch Res Notices. 2014;2014:839681.
17. Smeds S, Löfström L, Eriksson $O$. Influence of nerve identification and the resection of nerves 'at risk' on postoperative pain in open inguinal hernia repair. Hernia. 2010;14(3):265-70

18. Wijsmuller AR, van Veen RN, Bosch JL, Lange JFM, Kleinrensink G], leekel I, et al. Nerve management during open hernia repair - reply. Brit J Surg. 2007;94(1):17-22

19. Alfieri S, Rotondi F, Di Giorgio A, Funagalli U, Salzano A, Di Miceli D, et al. Influence of preservation versus division of ilioinguinal, iliohypogastric, and genital nerves during open mesh herniorrhaphy: prospective multicentric study of chronic pain. Ann Surg. 2006;243(4):553-8.

20. Mazin |B. Causes of postoperative pain following inguinal hernia repair: what the literature shows. [cited 2019 Mar 5]. Available from: https://www. practicalpainmanagement.com/causes-postoperative-pain-following-inguinal-hernia-repair-what-literature-shows

21. Douek M, Smith G, Oshowo A, Stoker DL, Wellwood IM. Prospective randomised controlled trial of laparoscopic versus open inguinal hernia mesh repair: five year follow up. BMI. 2003;326(7397):1012-3.

22. McCormack K, Scott NW, Go PM, Ross S, Grant AM; EU Hernia Trialists Collaboration. Laparoscopic techniques versus open techniques for inguinal hernia repair. Cochrane Database Syst Rev. 2003:CD001785.

23. Koning GG, Wetterslev J, Van Laarhoven C), Keus F. The totally extraperitoneal method versus Lichtenstein's technique for inguinal hernia repair: a systematic review with meta-analyses and trial sequential analyses of randomized clinical trials. PloS One. 2013;8(1):e52599. 